\title{
Another Brick in the Wall: Healthcare Access Difficulties and Their Implications for Undocumented Latino/a Immigrants
}

\author{
Thania Galvan ${ }^{1} \cdot$ Sarah Lill ${ }^{2}$ Luz M. Garcini ${ }^{2,3}$ \\ Accepted: 10 March 2021 / Published online: 23 March 2021 \\ (c) The Author(s), under exclusive licence to Springer Science+Business Media, LLC, part of Springer Nature 2021
}

\begin{abstract}
The mounting evidence highlighting the disproportionate impact of the COVID-19 pandemic in ethnic minority communities underscores the need to understand how distress and healthcare access impacts the well-being of undocumented Latino/a immigrants (ULIs), one of the most marginalized and vulnerable ethnic minority communities in the U.S. We used existing data from a cross sectional study (Proyecto Voces) of 252 ULIs to conduct path analyses that explored the relations among distress due to immigration legal status, healthcare access difficulties, and the health of ULIs. Results demonstrated that distress due to immigration legal status is related to the physical and mental health of ULIs, and that difficulties in accessing healthcare explained these relations. These data support the importance of immediate, targeted efforts for increasing access to healthcare among undocumented immigrants and highlight the long-term importance of a much-needed healthcare reform for improving access to marginalized populations.
\end{abstract}

Keywords Health disparities $\cdot$ Healthcare reform $\cdot$ Latino/a $\cdot$ Undocumented

\section{Introduction}

New studies using advanced demographic modeling suggests that approximately 22.1 million undocumented immigrants reside in the United States (U.S.) [1]. The majority of these immigrants identify as Latino/a and have lived in the U.S. for more than 10 years [2]. Despite their established presence, undocumented Latino/a immigrants (ULIs) in the U.S. continue to be disproportionally at-risk for diminished health outcomes [3-5]. Potential reasons for this have been proposed with the most notable being restricted access to healthcare and greater, more prolonged exposure to high levels of distress due to their immigration legal status [6, 7].

Thania Galvan

thania.galvan@du.edu

1 Department of Psychology, University of Denver, $2155 \mathrm{~S}$ Race St, Denver, CO 80210, USA

2 Center for Research To Advance Community Health, Joe R. and Teresa Lozano Long School of Medicine, The University of Texas Health Science Center at San Antonio, San Antonio, TX, USA

3 Department of Medicine, Joe R. and Teresa Lozano Long School of Medicine, The University of Texas Health Science Center at San Antonio, San Antonio, TX, USA
Unfortunately, research to test the aforementioned associations using advanced quantitative methodology is limited. Turning to existing qualitative literature documenting the effects of prolonged distress on health outcomes, it stands to reason that there will be a strong relation between distress due to immigration legal status and the health of ULIs [e.g., $8,9]$. The use of advanced quantitative methodologies to build upon knowledge gathered from qualitative studies is of the utmost importance for promoting the well-being of this sizeable, yet highly at-risk population, particularly in face of public health crises such as the COVID-19 pandemic.

One challenge, encountered by many ULIs, that may explain the relation between distress due to immigration legal status and diminished health outcomes, is their limited access to healthcare. Indeed, extensive research has demonstrated that limited healthcare access is particularly detrimental to the health of ULIs due to the numerous barriers that these immigrants encounter when seeking care [7, 10-12]. For example, because ULIs are ineligible for federally subsidized public health insurance programs, typically hold jobs that do not provide private health insurance, are unable to use safety net services due to fear of deportation and do not generally benefit from legislative efforts that aim to increase healthcare access via increased access to health insurance coverage (e.g., Affordable Care Act), many delay 
seeking medical care in an attempt to avoid the exorbitant financial cost associated with health services [13-15]. Additionally, limited English proficiency, difficulty navigating complicated health care systems, experiences with discrimination, and a general distrust of systems adds to the long list of barriers that further hinders this populations' ability to utilize health services [13]. These barriers may be compounded by policies and laws, which raises additional doubts within this population to use or access governmental benefits if/when they are eligible for them. An example of such a policy is the public charge policy which was put into place in August of 2019 and states that an immigrant who has received one or more public benefit for more than 12 month in any 36-month period may be denied lawful admission into the U.S. as they may be deemed a "public charge" [16]. Delays in seeking health services or a complete lack of healthcare may account for the negative effect that distress due to immigration legal status may have on the physical and mental well-being of ULIs, thus placing this already vulnerable population at even greater risk for diminished health outcomes. Research testing these hypothesized relations, however, has not been conducted. Such work is timely and necessary in the face of public health crises such as COVID19 when access to healthcare is particularly restricted, even among those who traditionally have encountered little to no difficulties in seeking care [17].

While the COVID-19 pandemic is affecting everyone, ULIs are at a heightened risk for being negatively impacted for several reasons. First, ULIs are vital to many of the industries considered "essential" during the COVID-19 pandemic (e.g., ULIs make up 53\% of the agriculture industry, $15 \%$ of the construction industry, $9 \%$ of the production industry, $9 \%$ of the service industry) $[18,19]$. Essential individuals have been largely unable to work from home through the height of the pandemic, which places them at greater risk for contracting COVID-19 [20]. The aforementioned risk of exposure, limited access to healthcare, and a greater likelihood of having an undiagnosed underlying health condition, increases the probability that ULIs face a more severe, potentially deadlier course of infection should they contract the virus [21-24]. Secondly, ULIs are at an increased risk for experiencing psychological distress due to the extended economic impact of COVID-19 increasing the likelihood of psychological distress. Like the general population, ULIs are impacted by the financial insecurity brought on by wage cuts, widespread layoffs, and company shutdowns [15, 25]. With the inability to access the economic relief offered as part of unemployment and stimulus benefits, ULIs are especially vulnerable to the well documented psychological effects of financial insecurity [26, 27]. Moreover, ULIs may also be susceptible to heightened distress as they are forced to make daily decisions about balancing their health and employment status. The aforementioned distress is further intensified by the fact that they are likely to work in industries where paid leave is not offered, social distancing and personal protective equipment (PPE) guidelines are difficult to enforce, and where their ability to self-advocate is stifled by their immigration legal status. These aforementioned risk factors underscore the importance of targeted interventions that will promote the well-being of ULIs during the COVID19 pandemic.

In light of the pressing need to better understand the associations among distress due to immigration legal status, healthcare access, and the health of ULIs, our study used existing data from a cross-sectional study of ULIs to examine these relations. The study analyzed data that was collected prior to the COVID-19 pandemic; the examination of data collected prior to the COVID-19 pandemic will characterize individual and system level factors that can elucidate the disproportional impact of the pandemic on Latinos, particularly ULIs. Given the literature reviewed, it was expected that distress due to immigration legal status would be associated with the health of ULIs such that greater distress would be related to poorer physical and mental health. It was also expected that healthcare access would mediate this relation. Results of this study are then applied to public health crises such as the COVID-19 pandemic to provide recommendations that will support the well-being of ULIs during times when healthcare access is of utmost importance.

\section{Methods}

\section{Participants and Sampling Design}

"Proyecto Voces" [Project Voices] is a multiphase, crosssectional study focused on understanding the physical and mental health of ULIs. Phase one of the project interviewed 254 ULIs residing in the greater San Diego area between November 2014 and January 2015. The study utilized a respondent driven sampling (RDS) approach for participant recruitment and data analyses, which enabled inference to a population of 22,000 ULIs in the target region [28]. In this study, recruitment began with three previously selected ULI or seeds. Seeds were identified by formative research and were selected to represent the diversity of the community including gender, age, place of residence and relevant immigration characteristics. From each seed, a recruitment chain began so that each seed was provided with three referral coupons to recruit other ULIs for participation. The next waves of recruits were provided with another set of three referral coupons to recruit additional participants and so on. Each referral coupon was coded to match the recruiter to the respondent and collected by the interviewer from each respondent in order to link respondent to seeds and referral chains but not to individual referrals. Sampling continued 
until the final subjects no longer matched the initial subjects in terms of demographic characteristics. To reduce biased estimates, RDS modifies commonly used chain-referral methods in three ways: (a) to increase the breadth of the social network captured by the sample, recruitment is limited by the use of coupons so participants are only allowed a fixed number of referrals (maximum of three); (b) in using referral coupons, participants do not personally identify referrals to the researcher so that anonymity is maintained; and (c) to make results representative of the target population (and not just respondents with large social networks), a systematic weighting scheme is built into the RDS model. A more complete description of RDS and its application to Proyecto Voces is provided by \{blinded \} and colleagues [3]. For the purposes of this study, data from phase one of Proyecto Voces was utilized in the current study's analyses.

Participant inclusion criteria for the initial Proyecto Voces study was: (1) at least 18 years of age; (2) able to speak English or Spanish during the interview; (3) self-identify as Latino/a by answering the question "do you identify yourself as Latino/a?" (4) not exhibiting symptoms of an acute psychotic episode (i.e., hallucinations, delusions, disorganized speech/thoughts) as assessed by observation and clinical judgement; and (5) undocumented status as determined by participant's responses to a series of yes/no questions outlining current legal statuses (i.e., citizen, legal or temporary resident, undocumented). Because two participants in the original study were missing data on the independent variable (i.e., distress due to immigration legal status), the current study sample is comprised of 252 participants.

\section{Data Collection}

All measures were completed in an in-person interview format by five trained bilingual psychology research assistants and graduate students who were under the direct supervision of a mental health clinician. These in-person interviews were done to facilitate the completion of study measures and to avoid participant's inability to complete study measures due to differences in their literacy abilities. All interviewers had extensive knowledge and experience in working with Latino/a and undocumented immigrant populations. Given the language preference for the majority of participants, interviews were conducted in Spanish. Interviews were conducted in locations identified by prior formative research as being convenient to participants (e.g., migrant shelters, participant's home, library, church, etc.). Respondents were compensated $\$ 30$ for their participation in the interview and $\$ 10$ for each referral (for a maximum of an additional \$30). Informed consent was obtained prior to participation and the study was approved by the San Diego State University's institutional review board.

\section{Measures}

\section{Distress Due to Immigration Legal Status}

Distress due to participants' undocumented status was measured via an adapted question taken from the DSM-V's cultural formulation interview [29]. The DSM-V cultural formulation interview is a four-question interview intended to understand distressing experiences among individuals of different backgrounds. The question used in this study (i.e., how much distress do you experience from not having a visa?) was adapted from the original interview in order to better understand the experience of undocumented immigrants. For the purposes of this study, distress was operationalized as the state of suffering associated with stressors, demands, or circumstances that are difficult to cope with in daily life. Participants were informed of this definition of distress and were asked to rate their level of distress on a scale from $0=$ no distress to $10=$ most distress. Higher scores are indicative of greater distress.

\section{Mental Health Symptoms}

Mental health symptoms were measured using the Brief Symptom Inventory-53 (BSI-53) [30]. The BSI-53 is a selfreport questionnaire that assesses for the presence of psychological symptoms across nine dimensions. This study used the depression and anxiety subscales. For each symptom, participants are asked to rate the level of distress that they have experienced in the past 7 days as a result of that symptom using a scale from $0=$ not at all to $4=$ extremely. Raw subscale scores were converted to standardized t-scores using gender specific community norms. The Cronbach's alpha for the subscales of interest in this study was acceptable (depression subscale, $\alpha=0.81$; anxiety subscale, $\alpha=0.71)$.

\section{Physical Health Symptoms}

The Bradford Somatic Inventory-23 (BSI-23) is a 23-item, self-report measure used to assess a wide range of participants' physical health symptoms [31]. For each symptom, participants were asked to rate the frequency with which they have experienced that symptom in the last month from $0=$ absent to $2=$ present 15 or more days this month. Higher scores are indicative of greater, more frequent physical symptoms with scores $\geq 14$ indicative of clinically significant physical symptoms. Estimates of specific health conditions are often difficult to obtain in this population as ULIs are unlikely to have access to a regular health care provider who can diagnosis such conditions [11]. Thus, this study focused on participants' self-report of physical symptoms as a proxy measure of their physical health status. The 
Cronbach's alpha for the measure in this study was excellent $(\alpha=0.90)$.

\section{Healthcare Access Difficulties}

Healthcare access difficulties were assessed via the PostMigration Living Difficulties (PMLD) Questionnaire [32]. The PMLD questionnaire is a 25 -item inventory used to assess adverse life experiences encountered by participants since their arrival to the U.S. The questionnaire was adapted based on information collected from pilot testing for phase one of Proyecto Voces. The total number of PMLDs related to healthcare access difficulties (i.e., 5 items) was used in this study. Items included "worries related to not having treatment for health problems," "difficulties in accessing emergency medicine," "difficulties in accessing long-term medical care," "difficulties in accessing dental care," and "difficulties in accessing a psychologist or counselor." Participants were asked to indicate whether or not they experienced a particular healthcare access difficulty $(0=$ no, $1=$ yes). A total score of the healthcare access difficulties endorsed by each participant was used with higher scores indicating greater healthcare access difficulties. The Cronbach's alpha for this questionnaire in this study was good $(\alpha=0.86)$.

\section{Covariates}

Because of their significant relation to the dependent variables, sex $(0=$ male, $1=$ female $)$ and marital status $(0=$ single or not partnered, $1=$ married, partnered, living as married) were included as covariates in analyses. These items were taken from the demographics and immigration history section of the study. No additional covariates were included in the analyses.

\section{Data Analysis}

Descriptive statistics and correlations were conducted to preliminarily explore the relations among mental health symptoms, physical health symptoms, healthcare access difficulties, distress due to immigration legal status, and covariates of interest. Inferential statistics accounted for RDS design effects and sample weights were used to produce weighted population estimates. Weights were calculated based on the percentage of ULIs that were expected to reside in the study location. The RDS Analyst software was used to test RDS assumptions and to generate RDS weights and population estimates [33]. Diagnostic testing for RDS assumptions confirmed that the characteristics of the study sample approximated those of ULI population in the greater San Diego area [34].
Hypothesized models were then tested via path analyses using Mplus Version 8 [35]. Goodness of fit indices were used to determine model fit. Good model fit was defined as a non-significant chi-square, a comparative fit index (CFI) of $>0.95$, and a Root Mean Square Approximation (RMSEA) of $<0.08$ [36, 37]. After model fit was established, the statistical significance and effect size of the individual pathway coefficients were used to interpret model results. Direct and indirect pathways were analyzed. Specifically, direct pathways from distress due to immigration legal status to mental and physical health symptoms, and those from healthcare access difficulties to distress due to immigration legal status and ULI's physical and mental health were examined. Whether participant's healthcare access difficulties mediated the relation between distress due to immigration legal status and the outcome variables was also tested. The model was tested using regression analyses with bootstrapped standard errors (iterations $=1000$ ), included covariances between the outcome variables, and controlled for participants' sex and marital status.

\section{Results}

\section{Descriptive Statistics and Bivariate Analyses}

Results from descriptive statistics, including population estimates, are presented in Table 1 . The average age of participants was 38.1 years old $(S D=11.1)$. The majority of the sample was female (69.3\%) and were partnered (i.e., married or living as married) $(68.1 \%)$. Average monthly income was $\$ 1,635.1(S D=\$ 852.8)$ and more than half of participants (65.0\%) had less than a high school education. Participants were largely of Mexican origin (97.6\%) and had spent an average of 16.4 years $(S D=8.0)$ living in the U.S. Despite the participants undocumented status, approximately $71.9 \%$ of participants indicated that they were living in a mixed status households with an average household size of 4.4 $(S D=1.9)$ individuals in the home. A mixed-status household is a household that includes people with difference citizenship or immigration statuses. Lastly, approximately $86.1 \%$ of the sample identified as parents and had an average of 2.8 children $(\mathrm{SD}=1.9)$.

Descriptive statistics also indicated that, on average, participants experienced a high level of distress due to their immigration legal status $(M=6.9, S D=3.1$, Range $=0-10)$. The average t-score for depressive symptoms was 54.3 $(S D=10.7$, Range $=41-90)$ and 49.5 for anxiety symptoms $(S D=11.1$, Range $=38-80)$. Further, participants had an average physical symptom score of 7.5 ( $S D=7.8$, Range $=0-42$ ) with approximately $19.0 \%$ of the sample having reporting clinically significant physical health symptoms. The average number of healthcare access difficulties 
Table 1 Participants' characteristics: Sample Characteristics and Weighted Population Estimates

\begin{tabular}{|c|c|c|c|c|c|c|c|}
\hline \multirow[t]{2}{*}{ Factor } & \multicolumn{2}{|c|}{ Sample $(n=252)$} & & \multicolumn{2}{|c|}{ Population $(\mathrm{N}=22,000)$} & \multirow[b]{2}{*}{$95 \% \mathrm{CI}$} & \multirow[b]{2}{*}{ SE } \\
\hline & $\mathrm{N}$ & $\%$ & & $\mathrm{~N}$ & $\%$ & & \\
\hline Sex & & & & & & & 0.05 \\
\hline Women & 174 & 69.3 & & 14,740 & 67.0 & {$[57.5 ; 75.8]$} & \\
\hline Men & 78 & 31.0 & & 7260 & 33.0 & {$[24.2 ; 42.5]$} & \\
\hline Education & & & & & & & 0.05 \\
\hline$<$ High school & 164 & 65.0 & & 14,520 & 66.0 & {$[56.3 ; 74.9]$} & \\
\hline$\geq$ High school & 88 & 34.9 & & 7480 & 34.0 & {$[25.1 ; 43.7]$} & \\
\hline Marital status & & & & & & & 0.04 \\
\hline Partnered & 171 & 68.1 & & 15,620 & 71.0 & {$[62.3 ; 79.3]$} & \\
\hline Not partnered & 81 & 32.1 & & 6380 & 29.0 & {$[20.7,37.7]$} & \\
\hline Country of birth & & & & & & & 0.01 \\
\hline Mexico & 246 & 97.6 & & 21,560 & 98.0 & {$[96.0,1.0]$} & \\
\hline Other & 6 & 2.4 & & 440 & 2.0 & {$[0.1,0.3]$} & \\
\hline${ }^{\mathrm{a}}$ Depressive symptoms & & & & & & & 0.04 \\
\hline Below clinical cut off & 196 & 77.8 & & 16,720 & 76.0 & {$[67.5,83.7]$} & \\
\hline At or above clinical cut off & 56 & 22.2 & & 5280 & 24.0 & {$[16.3,32.5]$} & \\
\hline${ }^{\mathrm{a} A n x i e t y}$ symptoms & & & & & & & 0.04 \\
\hline Below clinical cut off & 211 & 83.7 & & 188,260 & 83.0 & {$[75.1,90.4]$} & \\
\hline At or above clinical cut off & 41 & 16.3 & & 3740 & 17.0 & {$[9.6,24.9]$} & \\
\hline${ }^{\mathrm{b}}$ Physical symptoms & & & & & & & 0.03 \\
\hline Below clinical cut off & 204 & 81.0 & & 18,260 & 83.0 & {$[76.0,89.2]$} & \\
\hline At or above clinical cut off & 48 & 19.0 & & 3960 & 18.0 & {$[10.8,24.0]$} & \\
\hline Parental status & & & & & & & 0.03 \\
\hline Children & 217 & 86.1 & & 18,436 & 83.8 & {$[90.3 ; 77.3]$} & \\
\hline No children & 35 & 13.8 & & 3,036 & 16.3 & {$[9.7 ; 16.3]$} & \\
\hline Country of origin & & & & & & & 0.01 \\
\hline Mexico & 246 & 97.6 & & 21,560 & 98.0 & {$[99.9 ; 96.2]$} & \\
\hline Other & 6 & 2.4 & & 440 & 2.0 & {$[3.8 ; 0.1]$} & \\
\hline Mixed status household & & & & & & & 0.05 \\
\hline Yes & 182 & 71.9 & & 14,256 & 64.8 & {$[74.7 ; 55.0]$} & \\
\hline No & 71 & 28.1 & & 7,744 & 35.2 & $45.0 ; 25.3]$ & \\
\hline & $\mathrm{N}$ & M & SD & $\mathrm{N}$ & M & $95 \% \mathrm{CI}$ & SE \\
\hline Age & 252 & 38.1 & 11.1 & 22,000 & 39.0 & {$[36.0 ; 42.0]$} & 1.54 \\
\hline Monthly income & 252 & $1,635.1$ & 852.8 & 22,000 & 1582.0 & {$[1414.9 ; 1748.3]$} & 85.1 \\
\hline Years in U.S & 252 & 16.4 & 8.0 & 22,000 & 17.7 & {$[15.7 ; 19.7]$} & 1.03 \\
\hline Distress due to legal status & 252 & 6.9 & 3.1 & 22,000 & 6.6 & {$[6.1 ; 7.2]$} & 0.3 \\
\hline Depressive symptoms & 252 & 54.3 & 10.7 & 22,000 & 54.8 & {$[52.7 ; 56.9]$} & 1.07 \\
\hline Anxiety symptoms & 252 & 49.4 & 11.1 & 22,000 & 49.2 & {$[47.1 ; 51.4]$} & 1.09 \\
\hline Physical symptoms & 252 & 7.5 & 7.8 & 22,000 & 7.3 & {$[5.7 ; 9.0]$} & 0.9 \\
\hline Healthcare access difficulties & 252 & 2.8 & 1.7 & 22,000 & 2.7 & {$[2.4 ; 3.0]$} & 0.2 \\
\hline
\end{tabular}

${ }^{a}$ BSI scores $<63$ were indicative of no clinically significant symptoms whereas scores $\geq 63$ were indicative of clinically significant symptoms

${ }^{\mathrm{b}}$ Bradford somatization scores $<14$ were indicative of no clinically significant symptoms whereas scores $\geq 14$ were indicative of clinically significant symptoms

experienced by participants was $2.8(S D=1.7$, Range $=0-5)$. A closer examination revealed that the majority of participants endorsed difficulties related to their ability to access regular healthcare ( $64.6 \%$ of participants), long-term healthcare (69.3\%), and dentistry care (60.0\%); however, many participants did not report difficulties in accessing emergency medical services (49.2\%) or in accessing mental health services (37.4\%). 
Bivariate analyses results are presented in Table 2. Briefly, results confirmed that all of the variables of interest were significantly related to one another. Results also revealed a negative association between mental health symptoms and sex, and between depressive symptoms and marital status. On the other hand, physical health symptoms were related to sex and marital status.

\section{Path Analyses}

Path analyses model exploring the direct and indirect relations among distress due to immigration legal status, healthcare access difficulties, and the physical and mental health symptoms of ULIs demonstrated good model fit, $\chi^{2}$ $(7)=10.60, p=0.16, \mathrm{CFI}=0.98, \mathrm{RMSEA}=0.05$. Pathway coefficients and their significance are provided in Fig. 1. Multivariate analyses revealed that distress due to immigration legal status was positively related to participant's anxiety symptoms $(\beta=0.20, p=0.001)$, depressive symptoms $(\beta=0.31, p<0.001)$, and physical symptoms $(\beta=0.23$, $p<0.001)$. This indicates that as distress due to immigration legal status increased participant's mental and physical health decreased. Results also found direct effects between healthcare access difficulties, and participant's anxiety $(\beta=0.19 p=0.001)$, depressive $(\beta=0.22, p<0.001)$, and physical symptoms $(\beta=0.19, p=0.001)$. Indeed, more healthcare access difficulties was related to poorer physical and mental health. Healthcare access difficulties were also related to distress due to immigration legal status $(\beta=0.28$ $p<0.001)$ such that greater distress due to immigration legal status was associated with more healthcare access difficulties. Lastly, healthcare access difficulties mediated the relation between distress due to immigration legal status and ULI's physical and mental health (anxiety symptoms: $\beta=0.06, p=0.008$; depressive symptoms $\beta=0.06, p=0.003$; physical symptoms: $\beta=0.05, p=0.01)$.

Ancillary results also revealed an effect of sex and marital status on ULI's health status. Specifically, participant sex was related to anxiety $(\beta=-0.30, p<0.001)$ and depressive $(\beta=-0.21, p<0.001)$ symptoms, as well as to physical

Table 2 Correlations between immigration status distress, physical symptoms, anxiety symptoms, depressive symptom, healthcare access difficulties and covariates

\begin{tabular}{|c|c|c|c|c|c|c|c|}
\hline Variables & 1 & 2 & 3 & 4 & 5 & 6 & 7 \\
\hline 1. Distress due to immigration legal status & - & & & & & & \\
\hline 2. Physical symptoms & $0.28 * * *$ & - & & & & & \\
\hline $\begin{array}{l}\text { 3. Anxiety symptoms } \\
\text { (t-scores) }\end{array}$ & $0.25 * * *$ & $0.57 * * *$ & - & & & & \\
\hline $\begin{array}{l}\text { 4. Depressive symptoms } \\
\text { (t-scores) }\end{array}$ & $0.37 * * *$ & $0.53 * * *$ & $0.64 * * *$ & - & & & \\
\hline 5. Healthcare access difficulties & $0.28 * * *$ & $0.26 * * *$ & $0.24 * * *$ & $0.31 * * *$ & - & & \\
\hline 6. Sex ${ }^{\mathrm{a}}$ & 0.36 & $0.17 * *$ & $-0.21 * * *$ & $-0.13^{*}$ & 0.03 & - & \\
\hline 7. Marital status ${ }^{\mathrm{b}}$ & 0.01 & $-0.16 * *$ & -0.09 & $-0.22 * * *$ & 0.01 & -0.06 & - \\
\hline Range & $0-10$ & $0-42$ & $38-80$ & $41-90$ & $0-5$ & $0-1$ & $0-1$ \\
\hline
\end{tabular}

${ }^{\mathrm{a}}$ Sex: $0=$ Male, $1=$ female ${ }^{\mathrm{b}}$ Marital Status: $0=$ not partnered, $1=$ partnered

${ }^{*} \mathrm{p} \leq 0.05, * * \mathrm{p} \leq 0.01, * * * \mathrm{p} \leq 0.001$

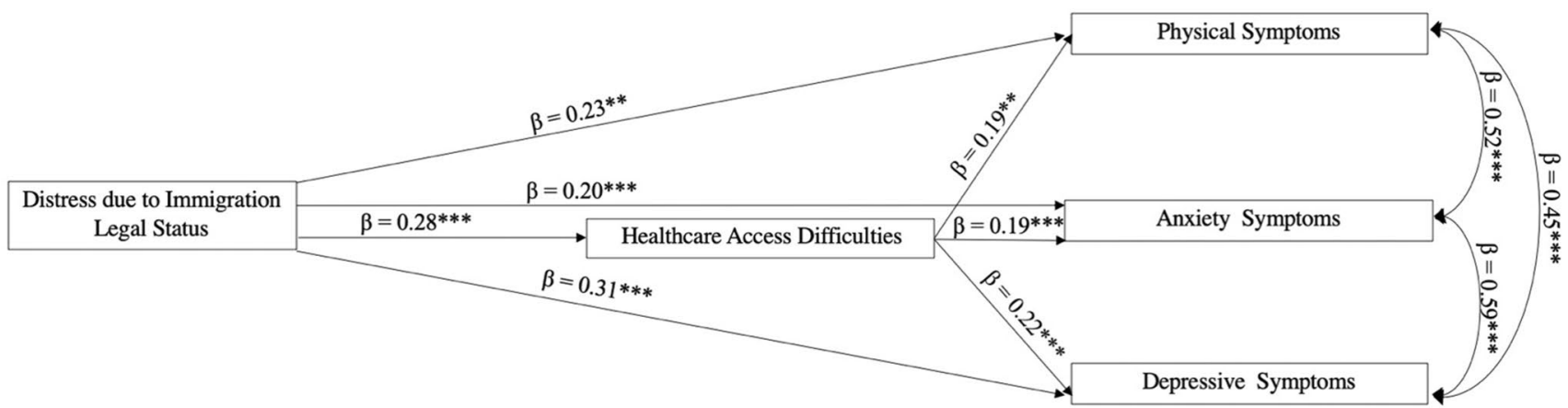

$\chi^{2}(7)=10.60, p=0.16, \mathrm{CFI}=0.98, \mathrm{RMSEA}=0.05$

Fig. 1 Path analyses for indirect effects model with standardized coefficients 
symptoms $(\beta=0.19, p=0.001)$. Indeed, males reported higher levels of anxiety and depressive symptoms whereas females reported greater and more frequent physical symptoms. Further, marital status was significantly related to depressive symptoms $(\beta=-0.32, p<0.001)$ such that participants who were not partnered reported greater depressive symptoms.

\section{Discussion}

In light of the pressing need to reduce health risk among ULIs, the present study explored how healthcare access difficulties influenced the relation between distress due to immigration legal status and their health. Our results supported our initial hypotheses by demonstrating that (1) increased distress due to immigration legal status was related to diminished physical and mental health among ULIs, and (2) healthcare access mediated these relations.

\section{Assessment of Results}

Placing our findings within the context of the literature, our results are consistent with those of a previous qualitative study that described the relation between distress due to legal status and diminished health outcomes in ULIs [4]. Through the use of quantitative analyses and sampling strategies that have been shown to reduce recruitment bias in research with hard-to-reach populations, we were not only able to confirm this relation but were also able to better understand the relation between these variables. ULIs often experience high levels of distress over a long time in large part due to high rates of trauma exposure pre- and post-migration, as well as from the constant threat of deportation that has been magnified over the past few years as a result of a surge in deportation rates and prevalent anti-immigrant actions/rhetoric in the U.S. $[3,10]$. The association between distress due to undocumented legal status and diminished health outcomes is likely to be strengthened in the face of additional compounded stressors, such as economic and health concerns from the COVID-19 pandemic. Given the well-established association between high levels of prolonged distress and negative health outcomes, exposure to compounded stressors is likely to make ULIs particularly vulnerable to some of the most dire health consequences associated with this pandemic $[8,9]$.

Descriptives of this study also revealed that ULIs faced the most difficulties with regular access to healthcare, longterm access to healthcare, and access to dentistry care. They, however, faced the least difficulties with access to emergency medical services or mental health services. With estimates suggesting that as many as $68 \%$ of undocumented immigrants lack health insurance coverage and that only about 1 in 5 ULIs having access to health insurance via their employer, it is perhaps not surprising that the health services that are deemed as preventative and/or require established care are also those that ULIs reported having the most difficulties with $[12,13,18]$. On the other hand, it is equally not surpring that ULIs reported that they encountered the least number of difficulties with emergency medical services as these services are typically available to most to some degree regardless of insurance status or immigration legal status $[12,38]$. Furthermore, referencing the robust literature suggesting that Latino/a do not seek mental health services at the same rate as their Non-Hispanic White counterparts and that they are more likely to receive mental health support from informal routes, it is also somewhat expected that participants would report the least number of difficulties in accessing this type of care $[39,40]$. This pattern of reported healthcare difficulties suggests that this population's physical health needs are largely reliant on emergency medical services-a difficulty which is likely exacerbated in the face of public health crises such as the COVID-19 pandemic. It also suggests that ULIs may rely on community-based, informal sources of support for their mental health needs. Access to these supports, however, may be reduced during the current pandemic due to social distancing guidelines and stay-at-home recommendations that limit interactions with those outside of one's immediate household.

Existing research has speculated that the relation between distress due to immigration legal status and diminished health outcomes among ULIs is largely due to difficulties in accessing healthcare. To our knowledge, no study has specifically tested this hypothesis. The present study filled this gap in the literature by demonstrating that, indeed, healthcare access mediates the relation between distress due to immigration legal status and health outcomes among ULIs. As previously mentioned, the difficulties that many ULIs have faced in accessing reliable healthcare are longstanding but have likely been intensified by anti-immigrant policies, such as the public charge policy. Though the U.S. Citizenship and Immigration Services (UCIS) has stated that care related to a COVID-19 diagnosis is not included in this public charge ruling, many ULIs may still remain hesitant to seek out medical care during these times as a) the symptoms of COVID-19 mimic the symptoms of other illnesses and this exception only applies to COVID-19 specific diagnoses, and b) the dissemination of information pertaining to this ruling has been limited in communities most impacted by the public charge rule $[41,42]$. The combination of this public charge rule and the increased demand on the healthcare system make it likely that healthcare access is even more restricted for undocumented immigrants, and that the relations demonstrated in this study may be exacerbated by the current pandemic. 


\section{Recommendations}

Considering our findings and their applicability to the health of ULIs now and in the future, we propose several recommendations that may ameliorate the negative health consequences highlighted by this study. These recommendations build off of the two mechanisms of change highlighted by our study-distress related to immigration legal status and difficulties accessing healthcare. To reduce distress related to immigration legal status, it is necessary to halt or significantly reduce anti-immigrant actions and policies so that ULIs feel safe to seek out the physical and mental health support they need without fear of repercussions. It will also be important to address the unique economic vulnerabilities facing this population; for instance, by improving working conditions to decrease occupational health risks. Of note, while these recommendations are likely to have a tremendous potential to reduce distress related to immigration legal status and its associated negative consequences, we recognize that putting these recommendations into place requires significant coordination between local, state, and federal government agencies. We also recognize that there may be differences in the degree to which local governments and organizations are equipped to respond to the needs of ULIs, and that these recommendations may need to be tailored to best meet the needs of local communities. Through strong civic engagement and advocacy, nonprofit organizations, health providers, and individual citizens will continue to be essential in pushing forward the needed changes.

Prompt action is also required to help promote access to healthcare among ULIs, especially during public health crises. Initiatives should aim to increase community outreach efforts to disseminate reliable, accurate, and timely health information and screenings in neighborhoods where many ULIs reside. These efforts should take extra precautions to ensure that the information and recommendations put forth (a) are made in consideration of Latino/a cultural values, contextual factors (e.g., limited resources, high risk jobs), (b) are available in both English and Spanish, and (c) highlight the separation of healthcare systems and immigration enforcement agencies. Additional initiatives should aim to increase access to health insurance coverage in this population by allowing undocumented immigrants to purchase health insurance in the marketplace, to increase resources to the safety net healthcare systems that serve their communities, to promote the use of telehealth services in this population, and to implement the widespread use of mobile healthcare clinics.

\section{Limitations and Future Directions}

Though our study makes important recommendations for promoting the health needs of a vulnerable immigrant population, especially during the current public health crisis, it is not without limitations. First, because of this populations' longstanding difficulties with healthcare access, estimates of chronic health conditions are difficult to obtain and are largely unreliable. While we believe that the use of physical symptoms as a proxy measure for participant's health status continues to be the best available measure of physical health in this population, we recognize that there is significant room for improvement in the way in which the physical health of ULIs is measured. This limitation further underscores the importance and need for addressing the recommendations put forth in this paper. Second, this study was cross-sectional, and causality could not be inferred. Future studies should aim to explore the relations examined in this study using a longitudinal design. Thirdly, it is important to recognize that geographical factors may have influenced the relations explored in this study (e.g., border communities may be more familiar with the needs of ULIs and, thus, healthcare may be more accessible in these areas). As such, additional research is needed to explore the way in which geographical location may influence these findings.

This study provides an important first step in understanding the way in which distress due to immigration legal status is linked to diminished health outcomes among ULIs. Future studies should aim to expand this understanding for instance by exploring how intersectional identities may increase vulnerability. Ancillary findings in this study showed an association between gender and marital status and the study outcomes, which should be further understood. Moreover, future studies should aim to expand an understanding of how common barriers associated with healthcare access (e.g., health insurance coverage, financial insecurity, distrust of systems) may influence the relation demonstrated in the present study.

\section{Conclusions}

To date, a limited number of initiatives have been put forth to support the health of ULIs, which is particularly important in the face of public health crises such as the current COVID-19 pandemic. Of initiatives that have been put forth, the vast majority have remained limited in scale and have primarily been undertaken by advocacy and/or nonprofit organizations [43, 44]. In light of our findings and the fact that the current pandemic is likely to strengthen the relations demonstrated in this study, additional efforts of a larger scale are needed to protect the health and wellbeing of this vulnerable population. Initiatives that target the distress that ULIs face as a result of their immigration legal status and the difficulties they encounter in accessing healthcare are especially needed to curb the dangerous health trajectory that this population is currently on. A call to action such as this one is 
of great importance from a public health and human rights standpoint both during the current pandemic and beyond.

Acknowledgements This work was supported by the National Heart, Lung, and Blood Institute (NHLBI) K01 Cardiovascular Disparities among Bereaved Latinos and Non-Latino Whites and Factors that Facilitate Resilience: A Biobehavioral Approach (PI: Luz M. Garcini, $\mathrm{PhD}, \mathrm{MPH}$ ).

\section{References}

1. Fazel-Zarandi MM, Feinstein JS, Kaplan EH. The number of undocumented immigrants in the United States: estimates based on demographic modeling with data from 1990 to 2016. PLoS ONE. 2018;13(9):e0201193.

2. Krogstad JM, Passel JS, Cohn D. 5 facts about illegal immigration in the U.S. in FactTank: News in numbers [Internet]. Washington: Pew Research Center; 2019. https://www.pewresearch.org/facttank/2019/06/12/5-facts-about-illegal-immigration-in-the-u-s/. Accessed 23 May 2020

3. Garcini LM, Galvan T, Malcarne V, Peña JM, Fagundes CP, Klonoff EA. Mental disorders among undocumented Mexican immigrants in high-risk neighborhoods: Prevalence, comorbidity, and vulnerabilities. J Consult Clin Psychol. 2017;85(10):927-936.

4. Gonzales RG, Suarez-Orozco C, Dedios-Sanguineti MC. No place to belong: Conceptualizing concepts of mental health among undocumented immigrant youth in the United States. Am Behav Sci. 2013;57(8):1174-99.

5. Martinez-Donate AP, Zhang X, Rangel MG, et al. Does acculturative stress influence immigrant sexual HIV risk and HIV testing behavior? Evidence from a survey of male Mexican migrants. J Racial Ethn Health Disparities. 2018;5:798-807.

6. Cavazos-Rehg PA, Zayas LH, Spitznagel EL. Legal status, emotional well-being and subjective health status of Latino immigrants. J Natl Med Assoc. 2007;99(10):1126-31.

7. Perez MC, Fortuna L. Psychosocial stressors, psychiatric diagnoses, and utilization of mental health services among undocumented immigrant Latinos. J Immigr Refug Serv. 2009;3(1-2):107-23.

8. Buckingham SL, Suarez-Pedraza MC. "It has cost me a lot to adapt to here": the divergence of real acculturation from ideal acculturation impacts Latinx immigrants' psychosocial wellbeing. Am J Orthopsychiatry. 2019;89(4):406-19.

9. Fernández-Esquer ME, et al. Living sin papeles: undocumented Latino workers negotiating life in "illegality." Hisp J Behav Sci. 2017;39(1):3-18.

10. Ornelas IJ, Yamanis TJ, Ruiz RA. The health of undocumented Latinx immigrants: what we know and future directions. Ann Rev Public Health. 2020;41:289-308.

11. Ortega AN, McKenna RM, Kemmick Pintor J, Langellier BA, Roby DH, Nadereh P, et al. Health care access and physical and behavioral health among undocumented Latinos in California. Med Care. 2018;56(11):919-26.

12. Bustamante AV, Fang H, Garza J, et al. Variations in healthcare access and utilization among Mexican immigrants: The role of documentation status. J Immigr Minor Health. 2012;14:146-55.

13. Heyman J, Núñez G, Talavera V. Healthcare access and barriers for unauthorized immigrants in El Paso County. Texas Fam Community Health. 2009;32(1):4-21.

14. Portney T, Ponce N, Sommer BD. Immigrants and the affordable care act: changes in coverage and access to care by documentation status. J Immigr Minor Health. 2020. https://doi.org/10. 1007/s10903-020-01124-0.
15. Artiga S, Diaz M. Health coverage and care of undocumented immigrants. San Francisco: Fairser Family Foundation; 2019. https://www.kff.org/racial-equity-and-health-policy/issuebrief/health-coverage-and-care-of-undocumented-immigrants/. Accessed 6 Dec 2020.

16. Public Charge Fact Sheet. Washington, DC: U.S. Citizenship and Immigration Services; 2020. https://www.uscis.gov/news/ public-charge-fact-sheet. Accessed 6 Dec 2020.

17. Emanuel EJ, Persad G, Upshur R, Thome B, Parker M, Glickman A, et al. Fair allocation of scarce medical resources in the time of COVID-19. N Engl J Med. 2020;382(21):2049-55.

18. Goldman DP, Smith JP, Sood N. Legal status and health insurance among immigrants. Health Aff. 2005;24(6):1640-53.

19. Dudley MJ. Why care about undocumented immigrants? For one thing, they've become vital to key sectors of the US economy. Waltham: The Conversation; 2019. https://theconversation. com/why-care-about-undocumented-immigrants-for-one-thingtheyve-become-vital-to-key-sectors-of-the-us-economy-98790. Accessed 6 Dec 2020.

20. Villa L. We're ignored completely: amid the pandemic undocumented immigrants are essential but exposed. New York: Time. 2020. https://time.com/5823491/undocumented-immigrantsessential-coronavirus/. Accessed 23 May 2020.

21. D'Alonzo K. The pandemic's effect on undocumented immigrants' health. Palmyra: Newswise. 2020. https://www.newsw ise.com/coronavirus/the-pandemic-s-effect-on-undocumentedimmigrants-health/?article_id=730395. Accessed 23 May 2020.

22. Barcellos SH, Goldman DP, Smith JP. Undiagnosed disease, especially diabetes, casts doubt on some of reported "health advantage" of recent Mexican immigrants. Health Aff. 2012;31(12):2727-37.

23. Zallman L, Himmelstein D, Woolhandler S, et al. Undiagnosed and uncontrolled hypertension and hyperlipidima among immigrants in the U.S. J Immigr Minor Health. 2017;15(5):858-65.

24. Martinez O, Wu E, Sandfort T, et al. Evaluating the impact of immigration policies on health status among undocumented immigrants: a systematic review. J Immigr Minor Health. 2015; 17:947-70.

25. Jan T. Undocumented workers among those hit first and worst by the coronavirus shutdown. Washington: The Washington Post. 2020. https://www.washingtonpost.com/business/2020/04/05/ undocumented-immigrants-coronavirus/. Accessed 23 May 2020.

26. Hackman M. Some tax-paying immigrants won't get coronavirus stimulus payments. New York: The Wall Street Journal. 2020. https://www.wsj.com/articles/some-tax-paying-immigrants-wontget-coronavirus-stimulus-payments-11585574259. Accessed 23 May 2020.

27. Kopasker D, Montagna C, Bender KA. Economic insecurity: a socioeconomic determinant of mental health. SSM Popul Health. 2018;6:184-94.

28. Heckathorn DD. Respondent Driven Sampling: a new approach to the study of hidden populations. Soc Probl. 1997;44(2):174-99.

29. American Psychiatric Association. Diagnostic and statistical manual of mental disorders. 5th ed. Arlington: American Psychiatric Publishing; 2013.

30. Derogatis LR. BSI Brief Symptom Inventory. Administration, Scoring, and Procedures Manual (4th ed.). Minneapolis: National Computer Systems; 1993.

31. Mumford DB, Bavington JT, Bhatnagar KS, Hussain Y, Mirza S, Naraghi MM. The Bradford Somatic Inventory: a multi-ethnic inventory of somatic symptoms reported by anxious and depressed patients in Britain and the Indo-Pakistan subcontinent. Br J Psychiatry. 1991;158:379-86.

32. Silove D, Sinnerbrink I, Field A, Manicavasagar V, Steel Z. Anxiety, depression and PTSD in asylum seekers: associations with 
pre-migration trauma and post-migration stressors. Br J Psychiatry. 1997;170:351-7.

33. Handcock MS, Fellows IE, Gile KJ. RDS Analyst: Software for the analysis of Respondent-Driven Sampling data. Version 0.42; 2014.

34. Demographics in the San Diego region. San Diego: San Diego Association of Governments; 2016. https://www.sandag.org/ uploads/publicationid/publicationid_2001_20213.pdf. Accessed 23 May 2020.

35. Muthén LK, Muthén BO. Mplus user's guide (6th ed.). Los Angeles: Muthén \& Muthén; 1998-2017.

36. Hu L, Bentler PM. Cutoff criteria for fit indexes in covariance structure analysis: Conventional criteria versus new alternatives. Struct Equ Model. 1999;6(1):1-55.

37. Kline RB. Principles and practice of structural equation modeling. 3rd ed. New York: Guilford Press; 2011.

38. Samra S, Taira BR, Pinheiro E, Trotzky-Sirr R, Schneberk T. Undocumented patients in the emergency department: Challenges and opportunities. West J Emerg Med. 2019;20(5):791-8.

39. Cabassa LJ, Zayas LH, Hansen MC. Latino adults' access to mental health care: a review of epidemiological studies. Adm Policy Ment Health. 2006;33(3):316-30.

40. Rios-Ellis B. Critical disparities in Latino mental health: transforming research into action. Long Beach: Institute of Hispanic Health; 2005. http://publications.unidosus.org/handle/123456789/ 1381. Accessed 6 Dec 2020.
41. Hlavinka, E. Public charge \& COVID-19: 'Perfect storm' for the undocumented. [Internet]. New York: Medpage Today; 2020. https://www.medpagetoday.com/infectiousdisease/covid19/86123. Accessed 6 Dec 2020.

42. Public Charge. Washington, DC: U.S. Citizenship and Immigration Services; 2020. https://www.uscis.gov/green-card/green-cardprocesses-and-procedures/public-charge. Accessed 6 Dec 2020.

43. Office of Governor Gavin Newsom. Governor Newsom announces new initiatives to support California workers impacted by COVID19. Sacramento: CA.Gov; 2020. https://www.gov.ca.gov/2020/04/ 15/governor-newsom-announces-new-initiatives-to-support-calif ornia-workers-impacted-by-covid-19/. Accessed 2020 May 23.

44. Immigrant worker safety net fund. Pasadena: National Day Laborer Organizing Network; 2020. https://ndlon.org/immigrantworker-safety-net-fund/. Accessed 2020 May 23.

Publisher's Note Springer Nature remains neutral with regard to jurisdictional claims in published maps and institutional affiliations. 